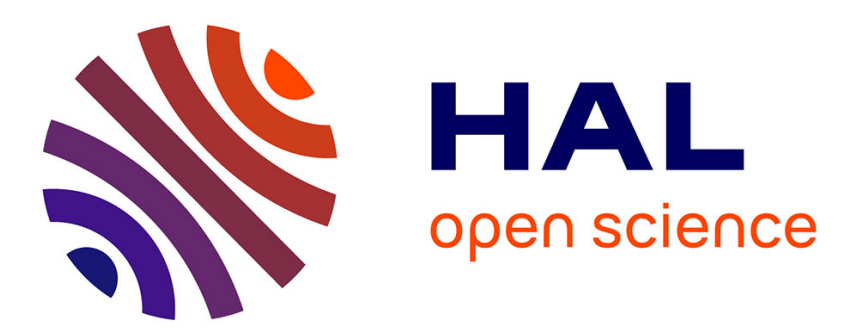

\title{
Growth and interface characterization of GaAs/GaAlAs superlattices
}

\author{
A. Regreny, P. Auvray, A. Chomette, B. Deveaud, G. Dupas, J.Y. Emery, A. \\ Poudoulec
}

\section{- To cite this version:}

A. Regreny, P. Auvray, A. Chomette, B. Deveaud, G. Dupas, et al.. Growth and interface characterization of GaAs/GaAlAs superlattices. Revue de Physique Appliquée, 1987, 22 (5), pp.273-278. 10.1051/rphysap:01987002205027300 . jpa-00245540

\section{HAL Id: jpa-00245540 https://hal.science/jpa-00245540}

Submitted on 1 Jan 1987

HAL is a multi-disciplinary open access archive for the deposit and dissemination of scientific research documents, whether they are published or not. The documents may come from teaching and research institutions in France or abroad, or from public or private research centers.
L'archive ouverte pluridisciplinaire HAL, est destinée au dépôt et à la diffusion de documents scientifiques de niveau recherche, publiés ou non, émanant des établissements d'enseignement et de recherche français ou étrangers, des laboratoires publics ou privés. 


\title{
REVUE DE PHYSIQUE APPLIQUÉE
}

Revue Phys. Appl. 22 (1987) 273-278

MAI 1987, PAGE 273

Classification

Physics Abstracts

$73.40 \mathrm{~L}-68.55-78.55-61.16 \mathrm{D}-61.10$

\section{Growth and interface characterization of GaAs/GaAlAs superlattices}

\author{
A. Regreny, P. Auvray, A. Chomette, B. Deveaud, G. Dupas, J. Y. Emery and A. Poudoulec \\ Centre National d'Etudes des Télécommunications, (LAB/ICM), 22301 Lannion, France
}

(Reçu le 21 octobre 1986, accepté le 18 décembre 1986)

\begin{abstract}
Résumé. - Le rôle de la qualité des interfaces dans les superstructures multiples puits quantiques (MQW) ou superréseaux (SR) a souvent été évoqué. Cependant, son importance a été, à notre avis, sous-estimée. Dans cet exposé nous montrerons comment la qualité de l'interface peut être améliorée dans les systèmes à base de GaAs et de GaAlAs. Nous verrons comment on a pu vérifier cette amélioration (en particulier pour l'interface inverse GaAs sur GaAlAs) ainsi que les conséquences d'une bonne qualité de l'interface sur certaines propriétés physiques des SR.
\end{abstract}

\begin{abstract}
The growth conditions of multi-quantum wells (MQWs) and superlattices (SLs) have been optimized and the characterization of the interface of high quality GaAs/GaAlAs and GaAs/AlAs superlattices has been performed. Electron microscopy, luminescence and X-ray diffraction show interfaces flat within one monolayer and only very large growth islands.
\end{abstract}

\section{Introduction.}

Many electronic and opto electronic devices have been realized using the ability of Molecular Beam Epitaxy (MBE) to produce heterostructures such as multiquantum wells (MQWs) or superlattices (SLs) composed of very thin GaAs and GaAlAs layers with abrupt interfaces. We recall that we differentiate MQWs from SLs with respect to their electronic properties : in a MQW, the carriers are confined to one well, in a SL, they are able to move through the GaAlAs barriers. The quality of the structures realized by the stacking of those very thin layers is mainly limited by a few factors : (i) the electronic properties of both materials (GaAs and GaAlAs), (ii) the reproducibility of the period which can be achieved by an accurate control of the shutters and growth rates, and (iii) the quality of the interfaces, this last parameter being of great importance. In this paper, we will describe the growth conditions which allow us to obtain flat interfaces with one monolayer fluctuations and large growth islands. The characterization of the interfaces was performed by X-ray diffraction, transmission electron microscopy (TEM) and photoluminescence spectroscopy. The agreement between the three methods is good, and $\mathrm{X}$-ray and TEM results confirm the interpretation of the luminescence in terms of interfacial disorder.

\section{Experimental.}

2.1 MBE [1]. - Samples are grown in a home modified MBE 500 RIBER. The chamber is provided with a load-lock system exchange for 4 samples which are processed in the same run to take advantage of the best conditions of pumping and cell temperature stabilization. The mechanical arrangement which allows a complete rotation of the shutters ensures an equal exposure time for each part of the sample. A great care was taken in the computer controlled shutter system : the opening times of the shutters are known with a precision better than $20 \mathrm{~ms}$ (growth rate $\simeq 2$ to $4 \AA / \mathrm{s}$ ). The substrate temperature is measured by a thermocouple which is in contact with the bottom of the molydenum substrate holder. Silicon doped « laser 
quality " GaAs wafers are used as substrates. After etching in a $\mathrm{H}_{2} \mathrm{SO}_{4}, \mathrm{H}_{2} \mathrm{O}_{2}, \mathrm{H}_{2} \mathrm{O}(3,1,1)$ solution, the substrates are held on the molydenum block with indium. The GaAs and GaAlAs layers grown in the standard conditions have a p-type residual doping level of about $10^{15} \mathrm{at} / \mathrm{cm}^{3}$.

2.2 X-RAY ChARACTERIZATION [2]. - The X-ray diffraction diagrams given by a superlattice (SL) as well as a multi-quantum well (MQW) lead to the determination of their structural parameters $n_{1}$, $n_{2}$ and $x$, respectively the number of monolayers in the barriers and in the wells and the aluminium content in the barriers. These diagrams are recorded using a $\theta / 2 \theta$ goniometer equipped with a postsample planar quartz monochromator and a doublecrystal diffractometer, in each case with a diffraction vector along the [001] growth direction.

The $C$ period of the superstructure is directly obtained from the experimental $\theta / 2 \theta$ scans. $C=$ $2 n_{1} d_{1}+2 n_{2} d_{2}$ where $2 d_{1}$ is the thickness of a GaAlAs monolayer grown by epitaxy and $2 d_{2}$ that of a GaAs one. $\left(2 n_{1} d_{1}=L_{\mathrm{B}}\right.$ and $\left.2 n_{2} d_{2}=L_{\mathrm{Z}}\right)$. In the same way, the average Al concentration $\bar{x}=$ $x \cdot \frac{n_{1}}{n_{1}+n_{2}}$ is directly deduced from the angular difference, measured on a rocking curve between the 004 reflections of the GaAs substrate and of the average lattice.

The values of $n_{1}$ (or $L_{\mathrm{B}}$ ), $n_{2}$ (or $L_{\mathrm{Z}}$ ) and $x$ are then determined by fitting calculated and experimental intensities of satellite peaks. A good test for this fit is the extinction of some satellites according to the values of $n_{1}$ and $n_{2}$ (for example, the extinction of even satellites when $n_{1}=n_{2}$ or more generally of satellites of $\pm k$-th order, where $k$ is a multiple of $\left(1+\frac{n_{1}}{n_{2}}\right)$, when $n_{1} / n_{2}$ is close to an integer).

2.3 TEM CHARACTERIZATION. - The TEM characterization of the interfacial quality has been reported by several authors $[3,4]$.

For such a study, $\{110\}$ cross sections, perpendicular to the growth plane, are prepared by mechanical thinning and ion milling after coating the samples with resin. The observations are performed on a JEOL 1200 EX [1] and a JEOL $100 \mathrm{C}$ equipped with a high resolution to entry stage [4].

The ability of the (002) reflexion dark field image to give a high diffraction contrast between $\mathrm{GaAs}$ and GaAlAs is well known [6]. GaAs layers appear dark whereas GaAlAs layers appear brighter as the aluminium content $x$ increases. This imaging mode promotes a direct observation of the whole thickness of a SL along the growth direction, and an evaluation of the interface roughness.

The high resolution observation mode allows us to study the interface structure at the atomic level $[5,7]$.

2.4 PhotoluminesCENCE (PL) EXPERIMENTS [8, 9]. - PL experiments are performed using an argon pumped dye Laser (LD 700) emitting in the 0.7-0.8 $\mu \mathrm{m}$ region. The samples are immersed in a flowing cryostat (Oxford Instruments CF 1204) allowing temperatures from $1.5 \mathrm{~K}$ to $300 \mathrm{~K}$. Detection is made by a GaAs photomultiplier and the monochromator focal length is $1 \mathrm{~m}$ (Jobin Yvon HR 1000). The usual power density on the samples is $10 \mathrm{~mW} / \mathrm{cm}^{2}$ and usually all experiments are performed at $2 \mathrm{~K}$.

2.5 RESUlTS AND DISCUSSION. - The optimization of the MQW or SL growth process was carried out, as proposed by Weisbuch et al., by using luminescence efficiency and PLE linewidth $[8,9]:$ a high luminescence intensity and a low linewidth are characteristic of a good sample.

The substrate temperature $\left(T_{\mathrm{s}}\right)$ and the V/III flux ratio were studied as parameters to optimize the growth conditions [12].

- In a first step, the quality and the surface morphology of GaAs and GaAlAs single layers were studied. For GaAs, we obtained high quality smooth layers with substrate temperature up to $700{ }^{\circ} \mathrm{C}$, provided that the $\mathrm{As}_{4}$ flux is sufficient to maintain As stabilization. For GaAlAs the PL spectra show low linewidth and intense excitonic recombinations only for substrate temperatures above $680^{\circ} \mathrm{C}$ and low V/III flux ratios $(\sim 4)$. However due to a 3dimensional growth, the surface of the samples remains still rough even at $T_{\mathrm{s}}=680^{\circ} \mathrm{C}$ [12].

- In a second step we have studied MQWs. Figure 1 shows the influence of substrate temperature and V/III flux ratios on luminescence properties of MQWs which parameters are listed in table I. When the substrate temperature increases from $620^{\circ} \mathrm{C}$ to $680^{\circ} \mathrm{C}$, the luminescence efficiency is improved by a factor of 60 (sample $d, c$ and b). At a given growth temperature of $680^{\circ} \mathrm{C}$, this efficiency is improved by a factor of 2 when the V/III flux ratio decreases from 15 to 4 (sample $b$ and a). These results must be compared to those of Weisbuch et al. [11]. The substrate temperature increase from $620^{\circ} \mathrm{C}$ to $680^{\circ} \mathrm{C}$ reduces the non-radiative recombination centers both in GaAlAs and at the interfaces, and the V/III flux ratio decrease, when the substrate temperature is held constant, improves mainly the interface smoothness.

This purpose is profusely illustrated by the TEM photograph of figure 2 showing the effect of the growth temperature on the interface smoothness. During the run, the substrate temperature was raised from $600{ }^{\circ} \mathrm{C}$ to $695^{\circ} \mathrm{C}$ as indicated on the TEM photograph. Below $680^{\circ} \mathrm{C}$ and especially in the temperature range $640{ }^{\circ} \mathrm{C} \leqslant T_{\mathrm{s}} \leqslant 680^{\circ} \mathrm{C}$ the in- 


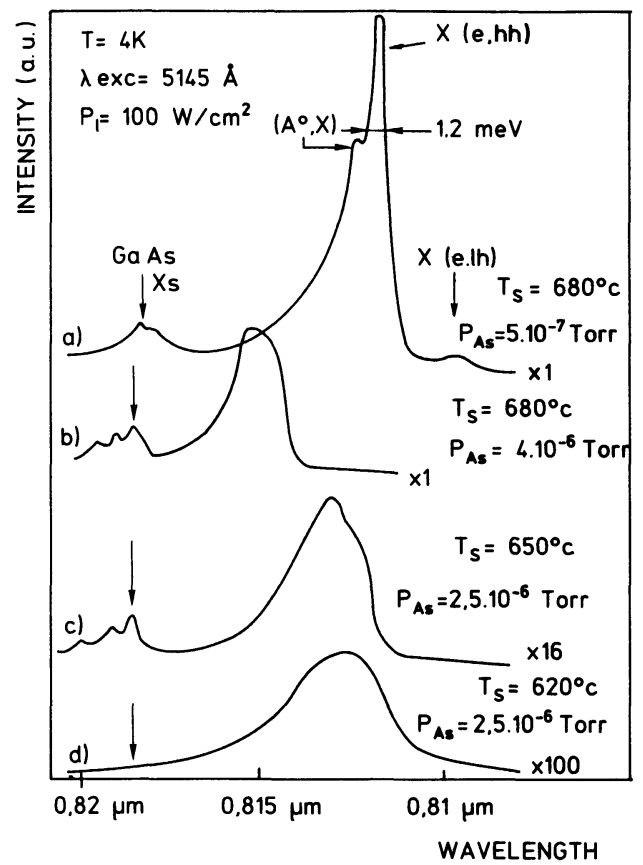

Fig. 1. - Comparison of the PL spectra of $4 \mathrm{MQWs}$ grown with different conditions of substrate temperature and As pressure.

Table I. - Parameters : $\mathrm{L}_{\mathrm{Z}}, \mathrm{L}_{\mathrm{B}}$ and $\mathrm{x}$ of the MQWs of the figure 1 .

\begin{tabular}{|c|c|c|c|}
\hline MBE & $\mathrm{L}_{\mathbf{Z}}(\AA)$ & $\mathrm{L}_{\mathbf{B}}(\AA)$ & $\mathrm{x}$ \\
\hline $210(\mathrm{a})$ & 195 & 138 & 0.31 \\
\hline $205(\mathrm{~b})$ & 218 & 141 & 0.3 \\
\hline $192(\mathrm{c})$ & 178 & 118 & 0.3 \\
\hline $190(\mathrm{~d})$ & 195 & 132 & 0.33 \\
\hline
\end{tabular}

terface morphology is disturbed by a 3-dimensional growth of GaAlAs while GaAs layers flatten the undulated interfaces. Above $680^{\circ} \mathrm{C}$, the interface roughness disappears, and for $695^{\circ} \mathrm{C}$, both interfaces (GaAs/GaAlAs/GaAs) seem to be equivalent.

The disappearance of roughness above $680^{\circ} \mathrm{C}$ has been related to the dissociation of $\mathrm{As}_{4}$ in $\mathrm{As}_{2}$ at the surface of the sample [13]. However this explanation does not hold for substrate temperatures below $640{ }^{\circ} \mathrm{C}$ which lead to less perceptible defects. It seems that the lifetime of the different chemical species on the surface must be taken into account. For this temperature domain, $\mathrm{Ga}$ adatoms have a high mobility but they are not reevaporated from the surface. The mobility of $\mathrm{Ga}$ atoms may allow the different chemical species to move on the surface and to be trapped in the favourable growth sites.

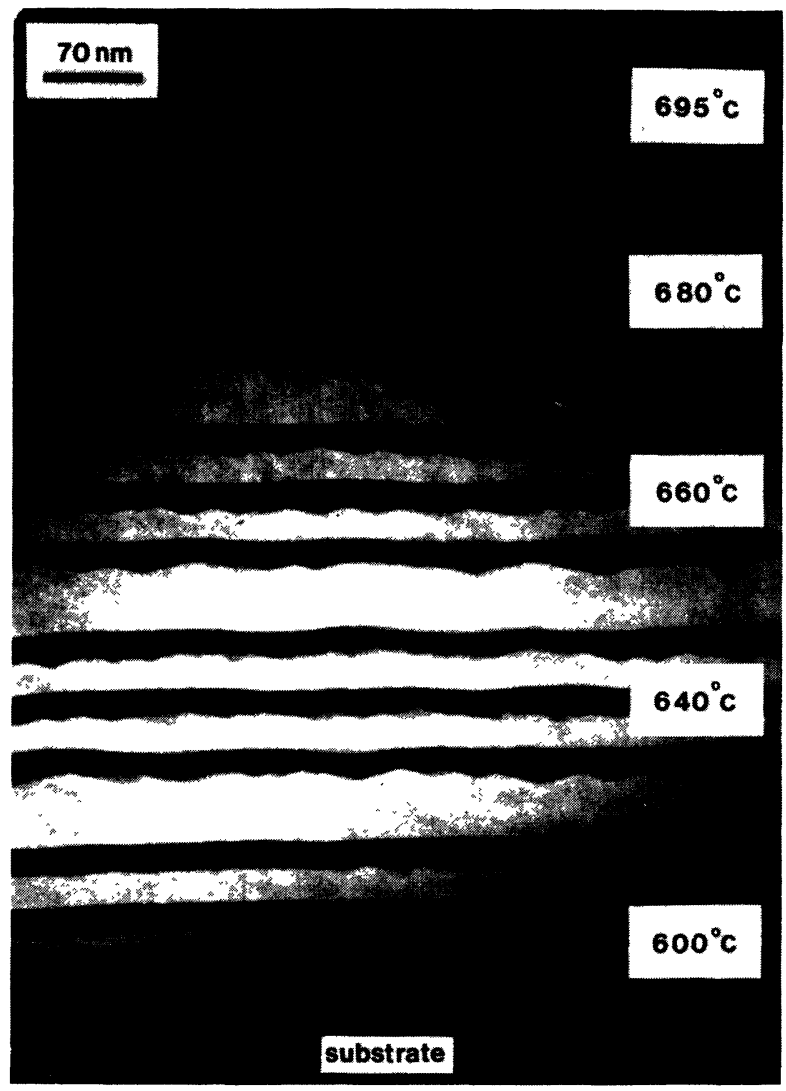

Fig. 2. - Dark field (110) TEM image of a GaAs/GaAlAs MQW grown at different temperatures as indicated.

This is supported by the fact that very smooth interfaces can be obtained at $600{ }^{\circ} \mathrm{C}$ with growth interruptions at the heterointerfaces $[14,15]$. Above $640{ }^{\circ} \mathrm{C}$ the surface lifetime of $\mathrm{Ga}$ adatoms is short [16] and they are rapidly reevaporated, if they are not trapped in favourable sites. In that case, $\mathrm{Ga}$ atoms cannot contribute to the movement of $\mathrm{Al}$ adatoms on the surface, $\mathrm{Al}$ atoms creating growth nucleations at their impinging place. Above $680^{\circ} \mathrm{C}$, $\mathrm{Al}$ adatoms can move easily on the surface to the favourable growth sites and moreover, $\mathrm{As}_{4}$ dissociation favours the 2-dimensional growth. Consequently the growth temperature was chosen about $695^{\circ} \mathrm{C}$ with a low V/III flux ratio.

With such conditions, good transport properties are obtained. Indeed, the vertical transport (i.e. the carrier motion along the growth axis) is a good test for the quality of a SL and the results obtained on such structures are in a good agreement with previous results $[17,18]$. Using standard luminescence, we have demonstrated on short period SL structures modified by the introduction of a few enlarged wells (EW), that the motion of photo-excited carriers across the barriers was possible [19]. Figure 3 is the comparison of the luminescence spectra of two 50/50 A SLs. In each superlattice, a few wells were 


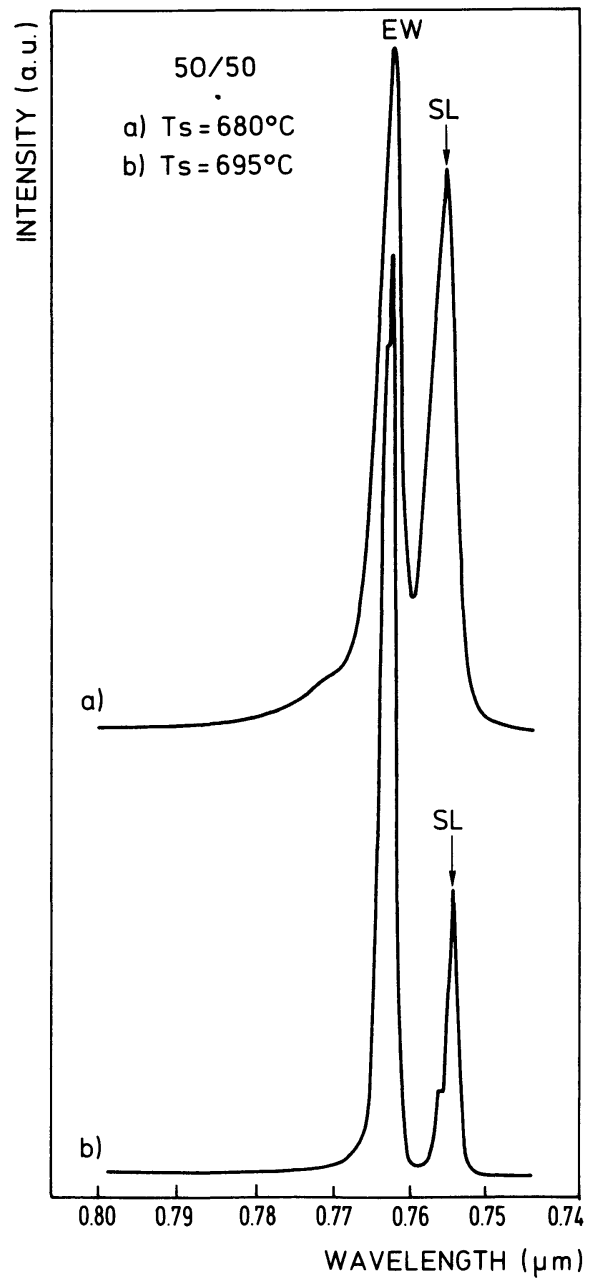

Fig. 3. - Comparison of the luminescence spectra of two 50-50 SLs, one enlarged well is introduced every $1400 \AA$. Sample a was grown at $680{ }^{\circ} \mathrm{C}$ and sample b at $695^{\circ} \mathrm{C}$. Vertical transport is favoured in sample b (better interfaces).

enlarged by three monolayers, the mean distance between two enlarged wells being kept constant and equal to $1400 \AA$. An enlarged well introduces in the SL band gap localized levels, the binding energy of which depends on the SL parameter and the size of the enlargement [19]. In figure 3, the two luminescence peaks correspond respectively to the SL and the EW. Sample a (upper curve) has been grown at $680{ }^{\circ} \mathrm{C}$. As this temperature is not optimized, the linewidth is quite large. Sample $b$ has been grown at $695^{\circ} \mathrm{C}$. It shows a much smaller linewidth and the appearance of a splitting of the exciton peaks both in the SL and the EW. This is explained by the occurrence of very large and only one-monolayer high interface growth defects $[8,11$, 20] (Fig. 4). This change in interface quality induces a better efficiency carrier transfer to the enlarged wells, evidenced by the change in the intensity ratio between EW and SL.

Luminescence experiments are in good agreement with high resolution transmission electron micro-

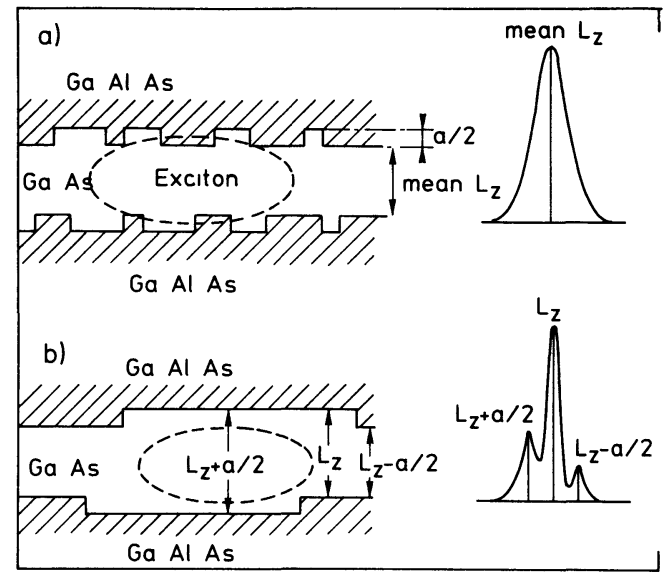

Fig. 4. - a) Effect of the interface disorder on the luminescence linewidth when the lateral size of the growth islands is smaller than the exciton Bohr diameter. b) When the lateral size of the growth islands is larger than the exciton Bohr diameter, the exciton only experiences one confinement energy corresponding to $L_{\mathrm{Z}}-a / 2, L_{\mathrm{Z}}$ and $L_{\mathrm{Z}}+a / 2$ and discrete peaks are observed in luminescence (see Fig. 3).

scope (HRTEM) observations. Figure 5 is a HRTEM image of a GaAs/AlAs superlattice, and the comparison between this image and a simulation $[7,21]$ allows us to ascertain the existence of atomic steps at the interfaces. Moreover, the simulation agrees with the observed contrast of the figure where atomic steps mostly appear on the reverse interface [21].

Using X-ray diffraction different small period superlattices have been studied. The results agree with good interfaces, since the diffraction due to the superperiod is evidenced down to a period of $8.10 \AA$ ( $L_{\mathrm{Z}}+L_{\mathrm{B}}=3$ monolayers) (Fig. 6).

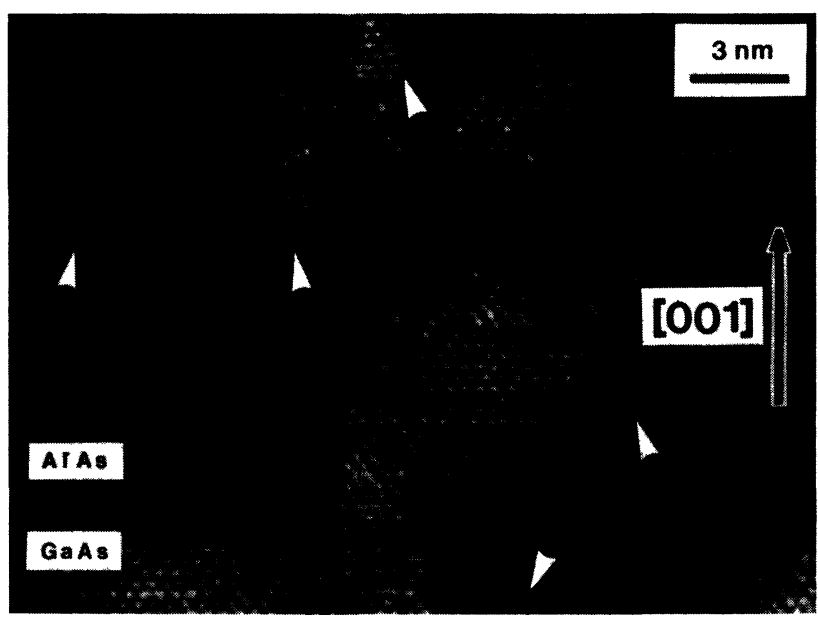

Fig. 5. - High resolution TEM image of GaAs/AlAs $(n 1+n 2=17)$ monolayers superlattices along [110]. The growing steps are marked by arrows. The steps are mainly located on the "reverse interface" (with courtesy of E.S.P.C.I. Paris). 


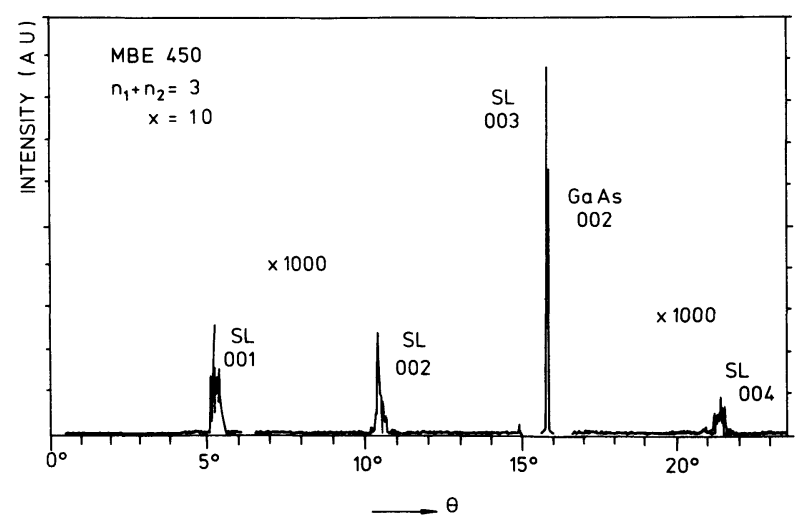

Fig. 6. - X-ray diagram of a 3 monolayer period $\mathrm{GaAs} / \mathrm{GaAlAs}$ superlattice.

However for superperiods lower than $80 \AA$, we notice a disagreement between calculated and observed intensity for the satellite peaks of the superlattices whereas the position of the diffraction peaks obtained on the $\theta-2 \theta$ goniometer agree perfectly with the period. To interpret these results, let us consider figure 7 which is a schematic model of a $4 / 4$ $(11,3 \AA / 11,3 \AA) \mathrm{GaAs} / \mathrm{AlAs}$ SL. It was set assuming that the deposited materials are proportional to the shutter opening times and remain constant during a run (this assumption has been verified). Assuming an interface roughness of one monolayer $L_{\mathrm{B}}(n 1)$ and $L_{\mathrm{Z}}(n 2)$ can take the three values 3,4
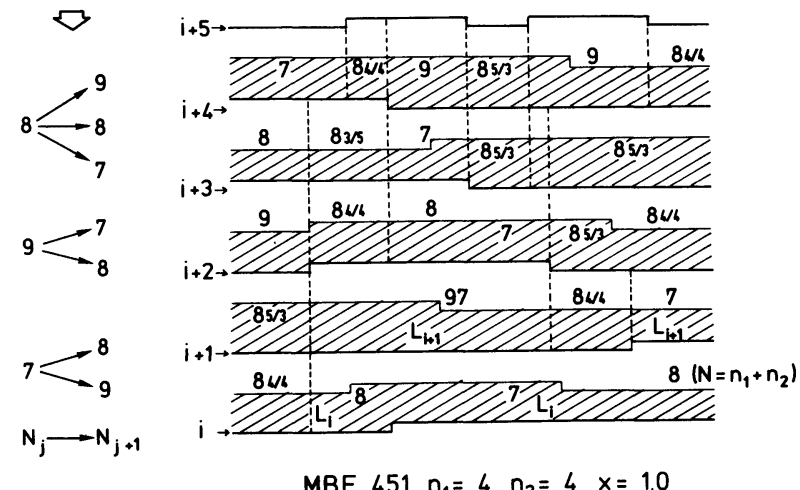

Fig. 7. - Schematic representation of a short period superlattice showing one monolayer thickness growth islands. and 5, but for their sum only the values 7,8 and 9 are possible. As a consequence all stacking sequences are not authorized as schematized in figure 7 . Only the zones surrounded by a dashed line contribute to the intensity at the Bragg positions for the satellite of the $n 1=n 2=4 \mathrm{SL}$, whereas the whole sample contributes to the average lattice diffraction peaks whose positions only depend on the aluminium content $x$.

The perfect SL model used to calculate peak intensities does not take this effect into account. Nor does it reflect the effect of gradients on $x$ and $C$, the latter being essential in the experimental diagrams of very short period SLs for geometrical reasons (i.e. the great difference in X-ray beam incident angle for the different satellites).

All these effects would have to be included in the theoretical calculations in order to explain observed intensities.

\section{Conclusion.}

We have optimized the growing conditions in order to produce high quality superlattices. High substrate temperatures $690^{\circ} \mathrm{C} \leqslant T_{\mathrm{s}} \leqslant 700{ }^{\circ} \mathrm{C}$ and V/III flux ratio as low as possible to maintain the arsenic stabilization are required. For the best samples discrete lines are observed on the PL spectra. They are induced by one-monolayer high growth islands at the interfaces. The island lateral size is found to be quite large ( $>300 \AA$ in diameter).

The HRTEM images and simulations confirm unambiguously the presence of monolayer steps which are mainly localized on the AlAs/GaAs interface.

The darkfield TEM images confirm that the range of $T_{\mathrm{s}}$ temperature $620{ }^{\circ} \mathrm{C}-680{ }^{\circ} \mathrm{C}$ has to be avoided to grow $\mathrm{GaAs} / \mathrm{GaAlAs}$ structures with smooth interfaces with an $\mathrm{As}_{4}$ source. The X-ray spectra of very small periods SLs exhibit an intensity attenuation of the satellite peaks which can also be due, at least partly, to local variations of the superperiod induced by one monolayer interface fluctuations.

\section{Acknowledgments.}

The authors would like to thank B. Guenais and M. Baudet for fruitful discussions and critical reading of the manuscript.

\section{References}

[1] Regreny, A., EMEry, J. Y., BAudet, M., Poudoulec, A., Auvray, P., Dupas, G., Deveaud, B. and Guenais, B., Semiconductor, Quantum well structures and superlattices, MRS Strasbourg (1985), edited by K. Ploog and N. T. Linh (les Editions de Physique) 1986.

[2] Kervarec, J., Baudet, M., Caulet, J., Auvray,
P., Emery, J. Y. and Regreny, A., J. Appl. Cryst. 17 (1984) 196.

[3] Petroff, P. M., Proceedings of the 11th international conference on GaAs and related compounds Biarritz (1984), edited by B. De Cremoux (Hilger Bristol), Inst. Phys. Conf. 74 (1985) 259. 
[4] Davies, J., Andrews, D. A., Br. Telecom. Technol. J. 3 (2) (1985) 59.

[5] Delamarre, C., Dubon, A., Laval, J. Y., GuENAIS, B. and EMERY, J. Y., Semiconductor, Quantum well structures and superlattices, MRS Strasbourg (1985), edited by K. Ploog and N. T. Linh (les Editions de Physique) 1986.

[6] Petroff, P. M., J. Vac. Sci. Technol. 14 (1977) 137.

[7] Laval, J. Y., Delamarre, C., Dubon, A., SCHIFFMACHER, G., De Sagey and Guenais, B., Proceedings of EMAG; Newcastle Upon Tyne 1985 (Hilger) Inst. Phys. Conf. 78 (1985) 359.

[8] Deveaud, B., Emery, J. Y., Chomette, A., LamBert, B. and BAudet, M., Appl. Phys. Lett. 45 (10) (1984) 1078.

[9] Deveaud, B., Regreny, A., Emery, J. Y. and Сhomette, A., J. Appl. Phys. 59 (5) (1986) 1633.

[10] Weisbuch, C., Dingle, R., Gossard, A. C. and Wiegmann, W., Solid State Commun. 58 (1981) 709.

[11] Weisbuch, C., Petroff, P. M., Dingle, R., GosSARd, A. C. and Wiegmann, W., Appl. Phys. Lett. 38 (1981) 840.

[12] EMERY, J. Y., Thesis Optimisation de la croissance en épitaxie par jets moléculaires du GaAlAs, des super-réseaux et des multi-puits quantiques GaAlAs/GaAs, Université de Rennes 1 $\mathrm{n}^{\circ}$ d'ordre 02 (1985).
[13] Erickson, L. P., Mattford, T. J., Palmberg, P. W., Fisher, R., MORKOC, H., Electron. Lett. 1916 (1983) 632.

[14] Fukunaga, T., Kobayashi, K. L., NaKashima, H., Japan J. Appl. Phys. 24 (1985) 510.

[15] Voillot, F., Madhukar, A., Kim, J. Y., Chen, P., Cho, N. M., TANG, W. C. and Newman, P. G., Appl. Phys. Lett. 48 (15) (1986) 1009.

[16] Fisher, R., KLEM, J., Drummond, T. J., ThORne, R. E., Kopp, W., MORKoc, H., CHO, J. Y., J. Appl. Phys. 39 (1968) 4032.

[17] Chomette, A., Deveaud, B., Emery, J. Y., LAMBert, B., RegrenY, A., Proceedings of the 1st International Conference on Superlattices and Related Works, Urbana, IL (1984), in Superlattices Microstruct. 1 (1985) 201.

[18] Deveaud, B., Chomette, A., Lambert, B., ReGRENY, A., Solid State Commun. 57 (1986) 885.

[19] Chomette, A., Deveaud, B., Emery, J. Y., REGRENY, A., Superlattices Microstruct. 1 (1985) 201.

[20] Goldstein, L., Yorikoshi, Y., Tarucha, S., OKAмото, H., Japan J. Appl. Phys. 22 (1983) 1489.

[21] Teste De Sagey, G., Shiffmacher, G., Laval, J. Y., Delamarre, C., Dubon, A., Guenais, B., RegrenY, A., to be published in the proceedings of the XIth International congress on electron microscopy. Kyoto (1986). 